\title{
Poetry, interpretation and unpredictability: a reply to Neil Pickering
}

Rolf Ahlzén and Carl-Magnus Stolt Karolinska Institute, Stockholm, Sweden

\begin{abstract}
In his article on poetry in health care education, Neil Pickering puts forward an argument of radical unpredictability: as we can never know in advance how a poem will be interpreted, it can be of no external use. ${ }^{1}$ It is, however, exactly this potential to give rise to multiple interpretations that makes the poem valuable. We hold that the poem should be read and discussed with no other intention than to discover and reflect on its possible meanings. Exactly this process, preferably in dialogue with other readers, may very well serve as one of the ends of the poem, and the results of it hence constitute its external use.

(F Med Ethics: Medical Humanities 2001;27:47-49)
\end{abstract}

The first issue of Medical Humanities contains articles which exemplify a wealth of interesting aspects of the relation between clinical medicine and the humanities. This is evidence as good as any for the vitality of this field. The articles invite rich reflection, and we trust that they will give rise to a continuing discussion. We will choose to focus mainly on Neil Pickering's extremely stimulating and perhaps somewhat playful - article, The use of poetry in health care ethics education. ${ }^{1}$ In the course of our argument we will also briefly comment on one other article in the issue. ${ }^{2}$

The crucial point that Pickering makes is that the reading of poetry is a profoundly uncertain activity in terms of its outcome. Poetry is of no use, he declares, since there is no external end which we can have any good reason to assume that it serves. There are, to be sure, "a number of candidates for such use", and he mentions some of them. However, the outcome of the meeting between reader and text is unpredictable. No instrumental use is therefore possible.

It is in fact not easy to place the demarcation line between "internal" and "external" use. If we interpret Pickering rightly, his point is that the only end for which we can use poetry is to understand it, and by this sometimes also experience enjoyment and being enriched. This may then be called its "internal end". We shall not expect this understanding, whatever form it may take, to do anything else for us. It will not serve any other purpose that we may hope to achieve. The poem can give enjoyment and enrich us, but it cannot be a means to any predictable end "outside" the poem (whatever could be meant by that). The reason for this is, as we just stated, that we cannot know anything about what sort of understanding will arise. Possibly, Pickering also means that our expectations that the poem will be useful for this or that particular end will make it particularly un-useful.

There is, at first glance, not much to say against Pickering's position. It is a defence of a widespread assumption in literary theory, namely that the meaning of a text arises in the encounter between reader and text: it resides neither in the text nor in the reader, but rather between them. Meaning is thus relational. The relation is complex to a degree that far exceeds our capacity to control. This is how Pickering underpins the unpredictability argument.

We think, however, that Pickering is very close to a conclusion that he surprisingly enough never reaches. In our opinion, it seems reasonable enough to assume that engaging in the activity of poetry reading, poetry discussion and poetry interpretation can serve external ends. By external ends we mean ends which are secondary to the activity of interpretation-and that of sharing interpretations - and which appear in situations other than those directly associated with the act of reading and discussing, for example in clinical settings. Such an external end may be a fuller, richer and more fruitful understanding of the different aspects of the clinical encounter.

If poems have such an open meaning structure, if we can expect them to give rise to a multitude of interpretations - does it not then seem very reasonable to say that the discovery of this world of interpretations is exactly the external end that poetry reading may serve? To put it another way: by reading and discussing poetry we are reminded that words, assembled in this case in a poetic form, carry an amazing number of possible meanings. We learn that in our own minds, and in comparison to other readers with whom we discuss the poem, very different interpretations may exist side by side. We learn, furthermore, that we can to some degree exchange interpretations when we engage in dialogue on texts. We are given a chance to notice both the possibilities and the limits of such an effort to reach out for common, or rather less different, horizons of meaning. We may occasionally, and perhaps not so seldom, even exchange horizonsthat is, more or less give up the interpretation that we held in favour of one that strikes us as more meaningful.

In short, if poetry, like other literary texts has this potential, it must certainly be eminently useful for clinical medicine, because the clinical meeting is an 
encounter where the interpretation of words is crucial. Scientific explanations intersect with historical narrative in the clinical encounter. ${ }^{3}$ The clinical challenge par excellence is, in our opinion, to be open to the patient's radical subjectivity, her ambiguity and complexity, and at the same time to apply the generalised, impersonal knowledge of scientific medicine. The clinician needs a language, and a mode of interpretation appropriate to both these aspects. Poetry reading can be a small but significant part of meeting this clinical challenge.

Pickering may object again, using the unpredictability argument. If, as we all agree, we cannot know how a poem may be interpreted, then neither may we know that "the insight of multiple interpretations" will arise, still less that it will in any way affect clinical practice. This is true. But we are talking of a potential. The insights that may come out of reflection on, and discussion of, poetry are not linked to any fixed meaning of the poem. They will not come by necessity, or even easily. A potential may be actualised, but it may also be lost. The potential inherent in the radical openness and hence unpredictability of literary texts will, we believe, be captured only by thorough reflection on what it means to read a text, how this experience relates to practice and how we may gain experience of how best to introduce such texts in educational situations. And the fact that we cannot be certain if this will finally affect clinical practice is not a great problem, is it? If it were, we would also have to give up the teaching of pharmacokinetics, membrane theory and consultation techniques. We expect no certain results from such activities, but good arguments and sound evidence support the assumption that they are useful, just as poetry reading is (in an altogether different, but complementary, way).

Let us exemplify with the help of Pickering's own example. Our impression of Pickering's own reading of the poem $A$ s expected is that it is sensitive and wise. Let us now assume that he is going to meet a class of medical students, that he gave them this poem some days earlier and that he invited them to read it, without any interpretational advice - in short, to read it as "freely" and as personally as possible. We assume that this discussion, maybe after some initial resistance and shyness, would provide Pickering and the other participants with numerous interesting interpretations, some of them rather different from his own. Now, if the purpose had been to discover and agree on what moral and exemplary conclusion to draw, this would have been irritating. This is not, however, what is being sought. Pickering, having cautiously presented some of his own interpretations, would instead lead the discussion towards a recognition of how interesting the differences in the ways of "reading" the poem are. He may ask for arguments and explanations, he may invite the group to follow lines of thought and associations, he may attempt clarifications, or possibly poetic rewriting. And he will surely be assisted all the time by a group that is more and more eager to find ways of presenting more or less different meaning horizons to each other. They will be surprised and happy when they succeed, and they may be a bit irritated and disappointed and bewildered when they do not. And if, as we hope, the group meets several times the poem will be like a living changing creature, taking on new forms and meanings continually. ${ }^{4}$

We must reiterate that we do not oppose the basic presumptions behind Pickering's unpredictability argument. We agree that there are far too many rather unreflective expectations that literary texts will do a certain job for us, teaching us or our students certain important lessons and so forth. We do think, however, that there is such a lesson, that this lesson is very general and unspecific-but nevertheless extremely important: human language is many layered and often ambiguous, and meaning is what comes out of the unique encounter between the text and the reader. We agree with the important point made by, among others, Fredrik Svenaeus, that we should beware of regarding the patient as a text. ${ }^{5}$ Still, and as stated above, we believe that the complex and very open generation of meaning from a text does have some important bearing on the patient-doctor encounter.

Perhaps our point is somewhat paradoxical and not so very far from Pickering's own conclusion: we hold that an individual or a group reading and discussing a poem should approach this poem with the single expectation of the poem that it is to be understood in its own right. There is then reason to expect a multitude of interpretations to arise (though we can, of course, not be sure of that). We believe that this is exactly the potential of the poem, and that it may very well be called its "external use", in the sense that we have tried to outline above.

If we are right in our assumptions, the literary texts that will be of use in health care education are texts that have a potential to give rise to multiple interpretations. This is, of course, the case for most texts. Chekhov, who was not a poet, is particularly interesting in this aspect, as his plays and short stories are so rich in meaning, so generous to varying interpretations. This brings us to Raimo Puustinen's very sympathetic Chekhov reading. ${ }^{2}$ We are here invited to reflect on the difference between what we would like to call an exemplary interpretation and a more complex and ambiguous reading. For however wisely Puustinen takes the reader by the hand - and it is very much a question of being led sensitively but firmly through the text - one may end with the question whether it was all so simple and clear. Are we here really dealing with a doctor who knows how to see the whole of the patient, an altogether attractive example of "person-oriented medicine"?

It is possible that we are. We do certainly not want to deny the value of this reminder of the need to overcome the "disease orientation" of physicians, which has certainly not become a lesser challenge during the more than one hundred years that have elapsed since Chekhov wrote his short story. But still: doesn't Chekhov really invite us to read his text 
as being full of sub-texts, of meanings and possibilities that are "below" the surface? Some of these may be: Is the doctor really wise to go to the patient's house? Why does he agree to stay there overnight? If he chooses to establish a closer relationship with the patient, is he prepared to take the consequences of the dependence and the expectations he thereby creates? And what are really his motives-what is professional responsibility, what is attraction, what is the wish for admiration and the search for the taste of power? May even the path that this doctor chooses at least partially exemplify that all-too-well-known problem of good intentions and bad outcomes, the tyranny of good will? Or is he perhaps choosing the least bad of a number of bad alternatives at hand? Being a good doctor is a task that is full of dangerous pitfalls; and "person-orientation" (or whatever we want to call it) is a risky and complicated business.

In short, while not denying the value of instructive readings we still believe that the most important potential in this short story-as in Tom Gunn's As expected, which Pickering considers-is its openness and the multitude of ambiguous interpretations to which it may give rise. ${ }^{1}$ Hence, we choose to see Puustinen's reading as a first reply in a long conversation that ideally will show more and more of the complexity of the text. It is valid, but other valid readings will appear as the dialogue goes on. The growing sum of these polyphonic readings will increase our understanding of that richness of meaning that is so crucial to clinical medicine.

Pickering and Puustinen are both voices in this polyphony and we are indebted to them for their invitation to join in.

Rolf Ahlzén is a General Practitioner and Lecturer in Medical Humanities, Department of Humanistic Medicine, Karolinska Institute, Stockholm, Sweden. Carl-Magnus Stolt is Professor of Humanistic Medicine, Department of Humanistic Medicine, Karolinska Institute.

\section{References and notes}

1 Pickering N. The use of poetry in health care ethics education. Medical Humanities 2000;26:31-6.

2 Puustinen R. Voices to be heard-the many positions of a physician in Anton Chekhov's short story A Case History. Medical Humanities 2000;26:37-42.

3 Toulmin S: Knowledge and art in the practice of medicine: clinical judgement and historical reconstruction. In Delkeskamp-Hayes C, Gardell-Cutter MA, eds. Science, technology and the art of medicine. Dordrecht: Kluwer, 1993: 231-49.

4 Wayne Booth calls this continuous process of evaluation and re-evaluation coduction. Some literary texts are peculiarly inviting to this form of ongoing reappraisal, making them alive in a very special sense. See Booth W. The company we keep: an ethics of fiction. Berkeley, Los Angeles, London: University of California Press, 1988: $70 \mathrm{ff}$.

5 Svenaeus F. Hermeneutics of clinical practice: the question of textuality. Theoretical Medicine and Bioethics 2000;21:171-89. 